\title{
Prevalence and factors associated with alcohol and tobacco use among non-institutionalized elderly persons
}

Marcelia Barezzi Barbosa'

Cláudio Vitorino Pereira² Danielle Teles da Cruz ${ }^{2}$ Isabel Cristina Gonçalves Leite ${ }^{2}$

\section{Abstract}

Objective: The present study aims to evaluate the prevalence of and factors associated with the use of tobacco and alcohol among elderly people living in the northern part of the city of Juiz de Fora, Minas Gerais, Brazil. Method: A cross-sectional study conducted through a home survey was performed with a sample of 423 elderly citizens. Interviews were conducted through a questionnaire including the Fagerström and Audit- $\mathrm{C}$ tests. The data were subjected to descriptive statistical analysis and multinomial regression. Results: The prevalence of elderly smokers was $9.0 \%, 32.0 \%$ were former smokers, $26.7 \%$ of the sample consumed alcoholic beverages and 3.2\% used alcohol and smoked. In the multinomial logistic regression model, the factors that were significantly associated with smoking were the male gender, an age of 60 to 70 years old; the presence of selfreported health problems; while the consumption of alcohol was associated with the male gender and frailty. Conclusion: There was a low prevalence of elderly people living in the community who consumed alcoholic beverages and/or were smokers. Such individuals, however, almost exclusively suffered from impaired health and potentially a poor quality of life. Regarding the profile of such elderly persons, there were similarities between the socio-demographic and health variables, suggesting the possibility of a more targeted approach to these individuals.

\footnotetext{
Universidade Federal de Juiz de Fora, Faculdade de Medicina, Programa de Pós-graduação em Saúde. Juiz de Fora, Minas Gerais, Brasil.

2 Universidade Federal de Juiz de Fora, Faculdade de Medicina, Departamento de Saúde Coletiva. Juiz de Fora, Minas Gerais, Brasil.
} 480163/2012-0).

Keywords: Demographic Aging. Health of the Elderly. Alcoholism. Tabacco Use Disorder. 


\section{INTRODUCTION}

Increased life expectancy is a global phenomenon with a number of repercussions for the care of the elderly, from direct care at home to the need for greater investment in public policies and programs, including the expansion of the basic care network aimed at this population ${ }^{1,2}$.

Although aging is a natural process, it also causes various anatomical and functional changes in the body, with effects on health conditions; the elderly may experience gradual cognitive loss and exhibit behavioral and emotional changes ${ }^{3}$.

For decades, tobacco consumption was tolerated and even admired. The mass media broadcast cigarette advertisements which reinforced a belief in the beauty, virility and masculinity of smoking, establishing the habit as a lifestyle. Today there is an emphasis on the harmful effects of smoking in television programs and magazine articles and newspapers. The change in the profile of information and media coverage over time is explained by the high morbidity and mortality rate ${ }^{3,4}$. In 2011, smoking was responsible for 147,072 deaths, 2.69 million years of life lost, 157,126 acute myocardial infarctions, 75,663 strokes and 63,753 diagnoses of cancer. The cost to the health system was $\mathrm{R} \$ 23.37$ billion. Monitoring the effects and use of tobacco has become an important strategy for strengthening public health policies ${ }^{5}$.

Alcohol consumption is the third biggest cause of illness and premature death worldwide ${ }^{6}$. While various forms of consumption classification exist, the ingestion of alcohol drinks by the elderly can be potentially harmful to health regardless of their pattern (quantity and frequency), even without the formal diagnosis of abuse or dependence ${ }^{7}$. The use of alcohol and drugs by elderly individuals can cause the worsening of their physical and/or mental state, social isolation and cognitive impairment ${ }^{8}$.

A Portuguese study showed that $6 \%$ to $11 \%$ of elderly patients admitted to general hospitals had symptoms of alcohol dependence?. The prevalence of smoking among the elderly, meanwhile, is lower than in adults ${ }^{10}$, due to the early death of smokers, the cessation of the habit with the onset of diseases and the choice to adhere to healthier behaviors. However, the absolute number of elderly smokers tends to increase with the aging of the population ${ }^{11}$.

The deleterious effects of smoking cause a reduction in life expectancy. Female smokers live for 4.47 fewer years than non-smokers, while men who routinely use tobacco have a 5.03-year reduction in life expectancy in comparison with non-smokers. In addition, smoking causes a reduction in quality of life due to the pathological conditions related to the habit ${ }^{12}$.

Smoking is particularly associated with consumers of alcoholic drinks ${ }^{13}$. This combination of exposure to risk factors predisposes the subject to significant alterations in visual and cognitive capacity, which cause personal and family suffering and high social costs $^{8}$.

However, few data exist in Brazil regarding the prevalence of smoking and alcohol consumption in the elderly population. The present study aims to evaluate the prevalence and factors associated with the use of tobacco and alcohol in a sample of elderly residents of the municipal region of Juiz de Fora (Minas Gerais).

\section{METHOD}

A cross-sectional population-based study was performed of non-institutionalized individuals aged 60 years and older living in the northern zone of the city of Juiz de Fora, Minas Gerais, Brazil. The sample is representative of the population of the municipal region, as the north zone is the largest region in the urban area and has the second largest quantitative population, as well as the largest number of neighborhoods and concentration of informal settlements and social programs. The present study originates from the second phase of a longitudinal study, the first phase of which was carried out in $2010^{14}$.

In this second phase of the study, the sample size required was calculated from the study developed in 2010 and data from the 2010 Census. Based on the multiple outcomes investigated in the current stage, the sample size was calculated based on a prevalence of $50 \%$, deff 1.5 (considering the cluster stratification 
effect) and a significance level of 95\%. The 2010 study was comprised of 420 elderly persons and the participants were selected by random stratified and cluster sampling in multiple stages. The primary units were the census tracts. For the draw, the sectors were grouped into strata defined in accordance with the different modalities of health care to which the population of the sector was assigned, subdivided into primary care (Family Health Strategy (FHS) or traditional), secondary care or areas without coverage. The selection of these sectors was performed independently with probabilities proportional to the size of each stratum.

For the 2014 survey, the calculation of the sample size was estimated from the data of the previous work and the results of the 2010 IBGE census based on the population of the area delimited at the level of census sector disaggregation. There were changes in the quantitative population and in the constitution of these sectors, which required the resizing of the representative probabilistic sample based on stratification and clustering. All the elderly participants of the first phase were visited again. The losses from population dynamics over the four years were compensated for by the oversampling method, respecting the sampling by clusters. Age, gender and level of education were the variables selected to determine the entry of new subjects.

Thus, 248 elderly persons included in the 2010 sample participated in the study, in addition to 175 new elderly persons, and the study was composed of 423 individuals. In cases where elderly persons did not reach the minimum score in the Mini Mental State Exam (MMSE), they were judged incapable of responding to the questionnaire, and their caregiver became the respondent (in this case the questions on self-perception were not answered). In the absence of another respondent, the elderly were excluded from the study.

The questionnaire used was previously standardized and tested through a pilot study with 50 elderly individuals residing in a region other than that selected for this survey, in order to verify the applicability of the instrument and to improve the interviewing technique of the researchers in a practical manner. Data collection took place in the home of the elderly between September 2014 and
March 2015. Quality control of the information collected was carried out, in which $10 \%$ of the sample was evaluated by a new partial interview.

Alcohol and/or tobacco consumption were considered as the dependent variables. The independent variables were grouped into three blocks: demographic and socioeconomic variables (Block 1: gender, age, schooling, self-reported skin color, marital status, socioeconomic level - Brazilian Association of Research Companies, Classification of 2013); variables related to the health of the elderly (Block 2: self-reported morbidities; frailty, measured according to the Edmonton Scale; suggestion of anxiety and/or depression, according to the Patient Health Questionnaire Scale (PHQ-4); falls) and variables related to the health service (Block 3: use of the Unified Health System - SUS, health plan, satisfaction with the medical health service, medical consultation in the last three months, hospitalization in the last three months, emergency service care in the last three months). The Fagerström Test and the Audit-C, respectively, were used to evaluate and classify the questions on tobacco and alcohol consumption, with both answered only by the elderly themselves.

Data were submitted to descriptive univariate analysis to obtain the frequencies and prevalences of the variables investigated. For the quantitative variables, measures of central tendency and dispersion were calculated. The chi-squared test was used in the bivariate analysis, with Rao-Scott correction. All analyzes were performed in an appropriate module for complex analysis.

The multivariate analysis was based on the proposed theoretical model of determination by hierarchical blocks of variables (Figure 1) to control possible confounding factors. According to literature, the hierarchical blocks were constructed with the demographic and socioeconomic variables included in the first block (distal determinants) included. These were responsible for conditioning the variables of the other levels of associated factors. The second block (composed of intermediate determinants) included questions regarding the health profile of the elderly, while the third block included the variables related to the health services. 
Variables that obtained a value of $p \leq 0.10$ were included in the bivariate analysis. The technique of the gradual withdrawal of variables based on significance levels was used, with those that maintained a value of $p<0.05$ remaining in the final model. To estimate the crude and adjusted odds ratios (OR), the multinomial logistic regression model was used, with a robust
The Guidelines and Regulatory Norms for Research Involving Human Beings were followed, in accordance with Resolution 466/2012 of the National Health Council. The Research Ethics Committee of the Universidade Federal de Juiz de Fora (the Federal University of Juiz de Fora) approved the study (Approval No. 771/916), which was financed by the National Council for Scientific and Technological Development (Process No. 480163/2012-0). All the elderly participants of this research read and signed the Free and Informed Consent Form. of the prevalence ratio.

Block 1: Demographic and socio-economic variables

Gender, age, skin color, socioeconomic level, marital status.

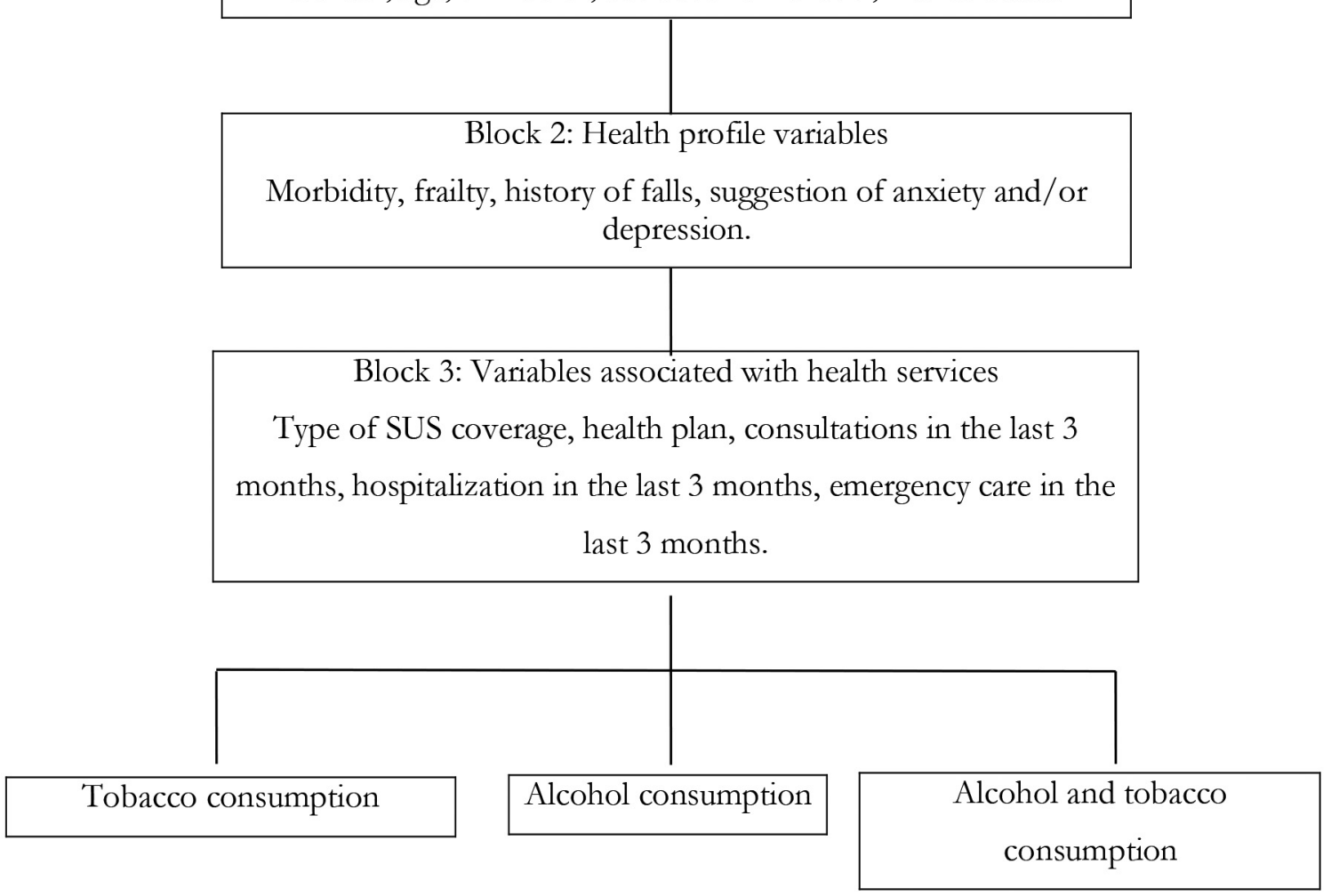

Figure 1. Theoretical research model of the association of independent variables with alcohol and/or tobacco consumption in hierarchical blocks. 


\section{RESULTS}

A total of 423 questionnaires were analyzed, of which 23 elderly persons were excluded due to a failing score in the MMSE and the absence of another respondent. The final sample consisted of 400 elderly individuals. A total of $315(78.8 \%)$ questionnaires were answered by the elderly themselves while 85 $(21.2 \%)$ were answered by another respondent. The comparison of the profiles of the elderly according to respondent indicated similarity between the groups, and so the questionnaires were analyzed jointly.

The participants, in terms of their sociodemographic characteristics, were mostly women $(64.5 \%)$, married or involved in a commonlaw-marriage (55.8\%), self-declared as white (45.5\%), with an average gross monthly family income between 1147.00 and 1685.00 reais $(59.0 \%)$. The mean age was 73.8 years $( \pm 8.0)$ with 4.2 years of schooling $( \pm 3.4)$. The presence of comorbidities was reported by $89.0 \%$ of the elderly, and $57.8 \%$ had some level of frailty (according to the Edmonton Scale). The suggestion of anxiety was identified in $72.7 \%$ of the elderly and the suggestion of depression in $77.1 \%$ (PHQ-4 Scale). In terms of health services, most of the elderly reported using the Unified Health System (96.5\%) and 60.3\% had health insurance. Of the elderly who used medical health services, $81.3 \%$ were satisfied with the service.

The characteristics of the sample according to the independent variables are described in table 1.

In terms of alcohol consumption, $26.7 \%$ of the elderly persons drank alcohol. Of these, according to the Audit-C classification, $78.6 \%$ consumed one standard dose while drinking, $83.3 \%$ never consumed eight or more standard doses at one time (binge, or heavy, alcohol use) and 5.4\% were classified as at risk consumers.
The prevalence of smoking was $9 \%$, of whom $58.3 \%$ had smoked for around 31 to 50 years, and the prevalence of ex-smokers was $32 \%$. The Fargeström Test was applied to the elderly smokers who were approved in the MMSE ( $\mathrm{n}=30$ ): $40 \%$ smoked their first cigarette of the day between six and 30 minutes after waking; $66.7 \%$ did not find not smoking in prohibited areas difficult; $70 \%$ stated that the first cigarette in the morning is the one that gives the most satisfaction; $56.7 \%$ smoked more in the early morning than during the rest of the day; $63.3 \%$ did not smoke when bedridden by illness; and $56.7 \%$ smoked less than ten cigarettes per day. In the consumption classification, $23.3 \%$ of the elderly persons exhibited a high degree of nicotine dependence. The prevalence of the elderly who used alcoholic beverages and who smoked was 3.2\% among those interviewed.

In block-adjusted multivariate analysis, the gender variable was statistically significant $(p<0.05)$ for both alcohol consumption and smoking in block 1 , while age was statistically significant for smoking only. In block 2 , the variables frailty and presence of a selfreported comorbidity were significant for alcohol consumption and smoking, respectively. In block 3 there were no statistically significant variables for any of the outcomes.

Table 2 shows the results following multinomial logistic regression analysis. The male gender variable (adjusted OR=2.14, 95\% CI 1.14-4.04/adjusted $\mathrm{OR}=2.23,95 \%$ CI 1.02-4.88) remained in the final model for alcohol consumption and smoking; the variables age (adjusted OR $=20.54,95 \%$ CI 2.69$157.08)$ and presence of self-reported comorbidities (adjusted OR=0.36, 95\% CI 0.13-0.99) remained for smoking; while the presence of frailty variable was maintained (adjusted OR $=0.31,95 \%$ CI 0.12-0.80) for the consumption of alcohol. 
Table 1. Sample characteristics according to independent variables. Juiz de Fora, Minas Gerais, 2016.

\begin{tabular}{|c|c|c|c|c|c|}
\hline \multirow{3}{*}{ Variables } & \multicolumn{2}{|c|}{ Alcohol Consumption } & \multicolumn{3}{|l|}{ Smoking } \\
\hline & Yes & No & Yes & No & $\mathrm{Ex}$ \\
\hline & $\mathrm{n}(\%)$ & $\mathrm{n}(\%)$ & $\mathrm{n}(\%)$ & $\mathrm{n}(\%)$ & $\mathrm{n}(\%)$ \\
\hline \multicolumn{6}{|c|}{ Block 1: Demographic and socioeconomic variables } \\
\hline \multicolumn{6}{|l|}{ Gender } \\
\hline Male & $42(39.6)$ & $64(60.4)$ & $13(9.2)$ & $49(34.5)$ & $80(56.3)$ \\
\hline Female & $42(20.1)$ & $167(79.9)$ & $23(8.9)$ & $187(72.5)$ & $48(18.6)$ \\
\hline \multicolumn{6}{|l|}{ Age } \\
\hline $60-70$ years & $37(27.2)$ & $99(72.8)$ & $25(15.9)$ & $84(53.5)$ & $48(30.6)$ \\
\hline $71-80$ years & $34(27.4)$ & $90(72.6)$ & $10(6.7)$ & $89(59.7)$ & $50(33.6)$ \\
\hline Over 80 years & $13(23.6)$ & $42(76.4)$ & $1(1.1)$ & $63(67)$ & $30(31.9)$ \\
\hline \multicolumn{6}{|l|}{ Schooling } \\
\hline Illiterate & $6(20.7)$ & $23(79.3)$ & $6(12.2)$ & $30(61.2)$ & $13(26.5)$ \\
\hline 1 to 4 years & $47(24)$ & $149(76)$ & $21(8.5)$ & $149(60.1)$ & $78(31.5)$ \\
\hline 5 years or more & $31(34.4)$ & $59(65.6)$ & $9(8.7)$ & $57(55.3)$ & $37(35.9)$ \\
\hline \multicolumn{6}{|l|}{ Marital Status } \\
\hline Married or common-law-marriage & $49(27.8)$ & $127(72.2)$ & $22(9.9)$ & $118(52.9)$ & $83(37.2)$ \\
\hline Other & $35(25.2)$ & $104(74.8)$ & $14(7.9)$ & $118(66.7)$ & $45(25.4)$ \\
\hline \multicolumn{6}{|l|}{ Socioeconomic Level } \\
\hline A or B & $29(32.6)$ & $60(67.4)$ & $7(6)$ & $67(57.3)$ & $43(36.8)$ \\
\hline $\mathrm{C}$ & $48(26.1)$ & $136(73.9)$ & $22(9.3)$ & $142(60.2)$ & $72(30.5)$ \\
\hline $\mathrm{D}$ or $\mathrm{E}$ & $7(16.7)$ & $35(83.3)$ & $7(14.9)$ & $27(57.4)$ & $13(27.7)$ \\
\hline \multicolumn{6}{|c|}{ Block 2: Variables related to health of elderly person* } \\
\hline \multicolumn{6}{|l|}{ Comorbidities } \\
\hline Presence & $71(25.4)$ & $208(74.6)$ & $29(8.2)$ & $217(61.1)$ & $109(30.7)$ \\
\hline Absence & $13(36.1)$ & $23(63.9)$ & $7(15.6)$ & $19(42.2)$ & $19(42.2)$ \\
\hline \multicolumn{6}{|l|}{ Illnesses of nervous system } \\
\hline Yes & $1(8.3)$ & $11(91.7)$ & $2(11.8)$ & $11(64.7)$ & $4(23.5)$ \\
\hline No & $70(26.2)$ & $197(73.8)$ & $27(8)$ & $206(60.9)$ & $105(31.1)$ \\
\hline \multicolumn{6}{|l|}{ Mental or behavioral disturbances } \\
\hline Yes & $1(4.2)$ & $23(95.8)$ & $5(12.5)$ & $31(77.5)$ & $4(10)$ \\
\hline No & $70(27.5)$ & $185(72.5)$ & $24(7.6)$ & $186(59)$ & $105(33.3)$ \\
\hline \multicolumn{6}{|l|}{ Circulatory system diseases } \\
\hline Yes & $56(27.5)$ & $148(72.5)$ & $21(8)$ & $158(60.5)$ & $82(31.4)$ \\
\hline No & $15(20)$ & $60(80)$ & $8(8.5)$ & $59(62.8)$ & $27(28.7)$ \\
\hline \multicolumn{6}{|l|}{ Respiratory system diseases } \\
\hline Yes & $2(15.4)$ & $11(84.6)$ & $2(11.1)$ & $11(61.1)$ & $5(27.8)$ \\
\hline No & $69(25.9)$ & $197(74.1)$ & $27(8)$ & $206(61.1)$ & $104(30.9)$ \\
\hline \multicolumn{6}{|l|}{ Endocrine system diseases } \\
\hline Yes & $15(19.5)$ & $62(80.5)$ & $10(9.8)$ & $61(59.8)$ & $31(30.4)$ \\
\hline No & $56(27.7)$ & $146(72.3)$ & $19(7.5)$ & $156(61.7)$ & $78(30.8)$ \\
\hline
\end{tabular}


Continuation of Table 1

\begin{tabular}{|c|c|c|c|c|c|}
\hline \multicolumn{6}{|c|}{ Osteomuscular system diseases } \\
\hline Yes & $16(20.3)$ & $63(79.7)$ & $7(7.4)$ & $61(64.9)$ & $26(27.7)$ \\
\hline No & $55(27.5)$ & $145(72.5)$ & $22(8.4)$ & $156(59.8)$ & $83(31.8)$ \\
\hline \multicolumn{6}{|l|}{ Neoplastic system diseases } \\
\hline Yes & $4(26.7)$ & $11(73.3)$ & $0(0)$ & $15(68.2)$ & $7(31.8)$ \\
\hline No & $67(25.4)$ & $197(74.6)$ & $29(8.7)$ & $202(60.7)$ & $102(30.6)$ \\
\hline \multicolumn{6}{|l|}{ Suggestion of Anxiety } \\
\hline Yes & $18(20.9)$ & $68(79.1)$ & $6(7)$ & $55(64)$ & $25(29.1)$ \\
\hline No & $66(28.8)$ & $163(71.2)$ & $24(10.5)$ & $127(55.5)$ & $78(34.1)$ \\
\hline \multicolumn{6}{|l|}{ Suggestion of Depression } \\
\hline Yes & $11(15.3)$ & $61(84.7)$ & $5(6.9)$ & $47(65.3)$ & $20(27.8)$ \\
\hline No & $73(30)$ & $170(70)$ & $25(10.3)$ & $135(55.6)$ & $83(34.2)$ \\
\hline \multicolumn{6}{|l|}{ Frailty } \\
\hline Present & $7(11.3)$ & $55(88.7)$ & $8(6.8)$ & $70(59.8)$ & $39(33.3)$ \\
\hline Absent & $63(32.6)$ & $130(67.4)$ & $21(9.5)$ & $130(58.6)$ & $71(32)$ \\
\hline \multicolumn{6}{|l|}{ Falls } \\
\hline Yes & $29(26.9)$ & $79(73.1)$ & $9(6.4)$ & $90(63.8)$ & $42(29.8)$ \\
\hline No & 55 (26.6) & $152(73.4)$ & $27(10.4)$ & $146(56.4)$ & $86(33.2)$ \\
\hline \multicolumn{6}{|l|}{ Continuous use medications } \\
\hline 1 to 4 medications & $49(28.8)$ & $121(71.2)$ & $22(10.8)$ & $119(58.3)$ & $63(30.9)$ \\
\hline More than 4 medications & $25(20.8)$ & $95(79.2)$ & $9(5.5)$ & $103(62.4)$ & $53(32.1)$ \\
\hline \multicolumn{6}{|c|}{ Block 3: Variables related to health service } \\
\hline \multicolumn{6}{|c|}{ Use of Unified Health System } \\
\hline Yes & $82(27)$ & $222(73)$ & $34(8.8)$ & $225(58.4)$ & $126(32.7)$ \\
\hline No & $2(18.2)$ & $9(81.8)$ & $2(13.3)$ & $11(73.3)$ & $2(13.3)$ \\
\hline \multicolumn{6}{|l|}{ Health Plan } \\
\hline Yes & $54(27.8)$ & $140(72.2)$ & $17(7.1)$ & $144(59.8)$ & $80(33.2)$ \\
\hline No & $30(24.8)$ & $91(75.2)$ & $19(11.9)$ & $92(57.9)$ & $48(30.2)$ \\
\hline \multicolumn{6}{|c|}{ Hospitalization in previous three months } \\
\hline Yes & $1(7.7)$ & $12(92.3)$ & $1(5.6)$ & $12(66.7)$ & $5(27.8)$ \\
\hline No & $83(27.5)$ & $219(72.5)$ & $35(9.2)$ & $224(58.6)$ & $123(32.2)$ \\
\hline \multicolumn{6}{|c|}{ Need for emergency care in previous three months } \\
\hline Yes & $8(23.5)$ & $26(76.5)$ & $5(11.6)$ & $25(58.1)$ & $13(30.2)$ \\
\hline No & $76(27)$ & $205(73)$ & $31(8.7)$ & $211(59.1)$ & $115(32.2)$ \\
\hline \multicolumn{6}{|c|}{ Medical consultation in previous three months } \\
\hline Yes & $61(25.3)$ & $180(74.7)$ & $25(8.2)$ & $186(61.2)$ & $93(30.6)$ \\
\hline No & $23(31.1)$ & $51(68.9)$ & $11(11.5)$ & $50(52.1)$ & $35(8.7)$ \\
\hline
\end{tabular}


Table 2. Consumption of alcohol and tobacco among the elderly population based on final variables. Juiz de Fora, Minas Gerais, 2016.

\begin{tabular}{|c|c|c|c|c|c|c|}
\hline \multirow{3}{*}{ Variables } & \multicolumn{2}{|c|}{ Consumption of alcohol } & \multicolumn{4}{|l|}{ Smoking } \\
\hline & Yes & & Yes & & Ex & \\
\hline & $\begin{array}{l}\text { Adjusted OR } \\
(\text { CI } 95 \%)\end{array}$ & $p$ & $\begin{array}{l}\text { Adjusted OR } \\
(\text { CI } 95 \%)\end{array}$ & $p$ & $\begin{array}{l}\text { Adjusted OR } \\
(\mathrm{CI} 95 \%)\end{array}$ & $p$ \\
\hline Gender & & 0.018 & & 0.045 & & $<0.001$ \\
\hline Male & $2.14(1.14 ; 4.04)$ & & $2.23(1.02 ; 4.88)$ & & $6.05(3.72 ; 9.84)$ & \\
\hline Female & 1 & & 1 & & 1 & \\
\hline Age & & & & $<0.001$ & & \\
\hline $60-70$ years & & & $20.54(2.69 ; 157.08)$ & & & \\
\hline 71 - 80 years & & & $7.37(0.91 ; 59.49)$ & & & \\
\hline$>80$ years & & & 1 & & & \\
\hline Comorbidities & & & & 0.047 & & 0.224 \\
\hline Presence & & & $0.36(0.13 ; 0.99)$ & & $0.63(0.30 ; 1.33)$ & \\
\hline Absence & & & 1 & & 1 & \\
\hline Frailty & & 0.015 & & & & \\
\hline Yes & $3.23(1.25-8.31)$ & & & & & \\
\hline No & 1 & & & & & \\
\hline
\end{tabular}

\section{DISCUSSION}

The data from this study describe the prevalence of alcohol and/or tobacco use in the city of Juiz de Fora, Minas Gerais. Smoking was more prevalent among men than women, as was alcohol consumption. The main findings regarding alcohol and tobacco consumption in relation to the demographic and socioeconomic variables were the prevalence of the male gender, while the age of 60-70 years variable predominated only in relation to smoking. In terms of the variables regarding health, the presence of frailty was statistically significant for the consumption of alcohol, while the presence of comorbidities was significant in terms of smoking.

A higher prevalence of alcoholics and smokers was found in male individuals in a population study in Brazi $^{11}$ and a study in Thailand ${ }^{15}$. Research conducted in the United Kingdom and the United States has also shown that the percentage of alcohol abuse is higher among men ${ }^{16,17}$.

Although poorly diagnosed and not adequately assessed, alcohol consumption is common among elderly individuals, and requires attention due to the increasing growth of this age group. Although actions in public health have mainly been aimed at identifying alcoholism among adults and young people, the physical, social, psychological and cognitive consequences of alcohol also affect the elderly. Cognitive disturbances (Alzheimer's and Parkinson's) caused by alcohol are more frequent among elderly people after long periods of consumption ${ }^{18}$.

The estimated prevalence of alcohol consumption in this age group is $10 \%$ in the community, $14 \%$ in hospital emergencies, 18\% in hospital admissions, and $23 \%$ to $44 \%$ in psychiatric units ${ }^{19}$. In the community under study a prevalence of $26.7 \%$ of elderly people who drink alcohol was found. It is important to investigate alcohol abuse by the elderly to achieve social and health improvements, as this can become a serious public health problem due to demographic and epidemiological transitions ${ }^{20}$.

Sensitivity to the effects of alcohol increases with age: the elderly may start to suffer problems from alcohol even if their consumption pattern remains the same ${ }^{21}$.

According to data from Vigitel, the prevalence of smoking in individuals aged 55 to 64 years was $13.5 \%$, whereas the percentage of smokers among those aged 
65 and over was $7.7 \% \%^{22}$, close to the findings for the population of the present study. Tobacco use is associated with worsening health status and quality of life, as well as being a risk factor for premature mortality and disability due to cardiovascular diseases, chronic obstructive pulmonary disease (COPD) and cancer, among other conditions ${ }^{23}$.

In terms of age group, it has been found that smoking is most prevalent in elderly persons aged between 60 and 69 years old ${ }^{24,25}$, which agrees with the data of the present study. As age increases, the percentage of smokers decreases ${ }^{26}$. Smoking is currently more prevalent among elderly men ${ }^{21,24}$, corroborating with the findings of the present study. Another study indicates a higher prevalence of the habit among elderly women, although these findings come from outpatient clinics which care for individuals who wish to quit smoking, which not only reflects a greater concern on the part of women for caring for their health, but also the seeking out of treatment aimed at stopping smoking ${ }^{26}$.

There are currently a number of pharmacological and non-pharmacological strategies to aid with quitting smoking, which may also be an alternative for the elderly ${ }^{27,28}$. No studies have been identified to date on the need for smoking groups exclusive to the elderly, but the participation of this population in quit smoking programs together with other age groups has been suggested, in order to favor the dynamics and the enrichment of the thematic repertoire and allow intergenerational relationships. Older people generally have fewer social ties than young people and adults, so a group approach is preferred, expanding their network of relationships, affective bonds, and interdependent relationships ${ }^{25}$.

Older smokers, who have survived the excessive rates of premature death from smoking, tend to be less motivated to quit the habit, underestimate the risks to their health and consider themselves to be relatively immune to tobacco-related harm ${ }^{29}$.

A strong association has been found in literature between smoking and alcohol consumption in the elderly ${ }^{24}$. However, few studies have investigated the trends and consequences of smoking and alcohol consumption in this population. A direct association between smoking and alcohol consumption in elderly people with depression has also been found ${ }^{30}$. In the present study, depression was significantly associated with alcohol consumption.

In a study conducted in Minnesota, the presence of frailty in the elderly, especially in the age group between 60 and 79 years, correlated with smoking and sometimes with concerns about alcohol consumption ${ }^{31}$. In the present study, however, the presence of frailty was associated only with alcohol consumption. Frailty is a term commonly used for elderly individuals at risk of precarious outcomes, although the concept is sometimes poorly or variably defined in literature, lacking both a consensual definition and clinical picture ${ }^{32}$.

The propensity of an individual to develop alcoholrelated diseases is linked to multiple dimensions such as the pattern and duration of consumption, and also in association with physiological, biological, psychological and social factors ${ }^{33}$.

Limitations of the present study include potential memory bias, considering the use of self-reporting by the elderly or caregivers, as well as its cross-sectional design, which does not allow the evaluation of temporal relationships or changes in exposure status over time. However, the importance of populationbased studies and the minimization of possible selection biases should be emphasized.

\section{CONCLUSION}

In the present study the prevalence of smoking was $9 \%$, that of alcohol consumption was $5.4 \%$, and that of the current use of tobacco and alcohol was $3.2 \%$. The profile most associated with the habits in question was elderly, younger and frailer men.

Elderly persons often become more vulnerable to alcohol and tobacco use, and such behavior can gradually result in a major public health problem as the number of older people in the world progressively increases. They are part of a group which suffers from various health problems and uses a number of medications, which, combined with the harmful substances present in tobacco and alcohol, make the elderly more susceptible to interactions, the aggravation of installed conditions and difficulties with recovery and social interaction. 
The prevalence of current smoking in the elderly decreases with advancing age, being more prevalent in the 60-70 year age range. The majority of smokers are elderly men rather than elderly women. The prevalence of alcohol consumption is equally distributed among age groups and, according to the alcohol consumption screening test, the majority do not fall within the risk of harmful consumption.

There is a shortage of theoretical instruments that discuss this issue in the elderly, with recent studies prioritizing young and adult smokers and alcohol users. Furthermore, when elderly smokers and/or

\section{REFERENCES}

1. Andrade LM, Sena ELS, Pinheiro GML, Meira EC, Lira LSSP. Public policies for the elderly in Brazil: an integrative review. Ciênc Saúde Coletiva. 2013;18(12):3543-52.

2. World Health Organization. World report on ageing and health. Geneva: WHO; 2015.

3. Vargas R, Barbosa RM, Tavares FA. Ilusão das imagens: olhar psicossocial sobre fumar nos filmes brasileiros. Psicol Soc. 2014;26(N. Esp):235-44.

4. Gus I, Ribeiro RA, Kato S, Bastos J, Medina C, Zazlavsky C, et al . Variations in the prevalence of risk factors for coronary artery disease in Rio Grande do Sul-Brazil: a comparative analysis between 2002 and 2014. Arq Bras Cardiol. 2015;105(6):573-79.

5. Pinto MT, Pichon-Riviere A, Bardach A. Estimativa da carga do tabagismo no Brasil: mortalidade, morbidade e custos. Cad Saúde Pública. 2015;31(6):1283-97.

6. Anderson P, Moller L, Galea G, editores. Alcohol in the European Union: consumption, harm and policy approaches. Copenhagen: WHO; 2012.

7. Pillon SC, Cardoso L, Pereira GAM, Mello E. Perfil dos idosos atendidos em um centro de atenção psicossocial: álcool e outras drogas. Esc Anna Nery. 2010;14(4):742-8.

8. Lintzeris N, Rivas C, Monds LA, Leung S, Withall A, Draper B. Substance use, health status and service utilisation of older clients attending specialist drug and alcohol services. Drug Alcohol Rev. 2016;35(2):223-31.

9. Serviço Nacional de Saúde. Direção Geral de Saúde. Plano Nacional de Saúde 2012 - 2016. [Sem local]: Ministério da Saúde; 2012. alcohol users are part of the sample, the results are related to prevalence, with other findings evaluated in a global manner and few investigations considering the trends and consequences of these habits among the elderly population.

Health actions and prevention and intervention policies should be planned using an integrated approach to social, psychological and biological factors, with a view to reducing alcohol abuse and smoking, as well as preventing its harmful effects on health.
10. Malta DC, Campos MO, Oliveira MM, Iser BPM, Bernal RTI, Claro RM, et al. Prevalência de fatores de risco e proteção para doenças crônicas não transmissíveis em adultos residentes em capitais brasileiras, 2013. Epidemiol Serv Saúde. 2015;24(3):373-87.

11. Doolan DM, Froelicher ES. Smoking cessation interventions and older adults. Prog Cardiovasc Nurs. 2008;23(3):119-27.

12. Pinto MT, Pichon-Riviere A, Bardach A. Estimativa da carga do tabagismo no Brasil: mortalidade, morbidade e custos. Cad Saúde Pública. 2015;31(6):1283-97.

13. Jiang N, Gonzalez ME, Ling PM, Glantz SA. Relationship of Smokefree Laws and Alcohol Use with Light and Intermittent Smoking and Quit Attempts among US Adults and Alcohol Users. PLOS ONE. 2015;10(10):1-17.

14. Cruz DT, Ribeiro LC, Vieira MT, Teixeira MTB, Bastos RR, Leite ICG. Prevalência de quedas e fatores associados em idosos. Rev Saúde Pública. 2012;46(1):138-46.

15. Tran TT, Yiengprugsawan V, Chinwong D, Seubsman S, Sleigh A. Environmental tobacco smoke exposure and health disparities: 8-year longitudinal findings from a large cohort of Thai adults. BMC Public Health. 2015;15:1-11.

16. Odermatt R, Stutzer A. Smoking bans, cigarette prices and life satisfaction. J Health Econ. 2015;44:176-94.

17. Silfen SL, Cha J, Wang JJ, Land TG, Shih SC. Patient characteristics associated with smoking cessation interventions and quit Attempt Rates Across 10 Community Health Centers With Electronic Health Records. Am J Public Health. 2015;105(10):2143-9. 
18. Carraro TE, Rassool GH, Luis MAV. Nursing formation and the drugs phenomenon in the South of Brazil: nursing students' attitudes and beliefs on care. Rev Latinoam Enferm. 2005;13(N. Esp.):863-71.

19. Rigo JC, Rigo JFO, Faria BC, Stein A, Santos VM. Trauma associated with alcohol use in the elderly. Brasília Méd. 2005;42(1/2):35-40.

20. Rao R, Schofield P, Ashworth M. Alcohol use, socioeconomic deprivation and ethnicity in older people. BMJ Open. 2015;5:1-6.

21. Silva AA. Alcoolismo em idosos. Rev Cient Elet Psicol. 2008;4(10):1-6.

22. Brasil. Ministério da Saúde. Vigitel Brasil 2016: vigilância de fatores de risco e proteção para doenças crônicas por inquérito telefônico. Brasília, DF: MS; 2017.

23. José BPS, Corrêa RA, Malta DC, Passos VMA, França EB, Teixeira RA, et al. Mortalidade e incapacidade por doenças relacionadas à exposição ao tabaco no Brasil, 1990 a 2015. Rev Bras Epidemiol. 2017;20 Supl. 1:75-89.

24. Senger AEV, Ely LS, Gandolfi T, Schneider RH, Gomes I, De Carli GA. Alcoholism and smoking in the elderly: relation to dietary intake and socioeconomic aspects. Rev Bras Geriatr Gerontol. 2011;14(4):713-9.

25. Santos SR, Gonçalves MS, Leitão Filho FSS, Jardim JR. Profile of smokers seeking a smoking cessation program. J Bras Pneumol. 2008;34(9):695-701.
26. Goulart D, Engroff P, Ely LS, Sgnaolin V, Santos EF, Terra NL, et al. Smoking in the elderly. Rev Bras Geriatr Gerontol. 2010;13(2):313-20.

27. Prochaska JJ, Benowitz NL. The Past, present and future of Nicotine Addiction Therapy. Annu. Rev. Med. 2016;67:1-21.

28. Phillips A. Supporting smoking cessation in older patients: a continuing challenge for community nurses. Bri J Community Nurs. 2016;21(9):457-61.

29. Pellizzon RF. Research in Health area: 1 - DeCS Database (Descriptors in Health Sciences). Acta Cir Bras. 2004;19(2):153-63.

30. Cavalcanti BM, Urbano RV, Brandt CT, Bravo Filho V, Ventura MC, Nose W. Visual impairment due to tobaco and alcohol consumption in elderly patients from the western countryside of Pernambuco State, Brazil. An Fac Med Univ Fed Pernamb. 2007;52(2):95-9.

31. Chamberlain AM, Sauver JL, Jacobson DJ, Manemann SM, Fan C, Roger VL, et al. Social and behavioural factors associated with frailty trajectories in a population-based cohort of older adults. BMJ Open. 2016;6:1-11.

32. Abellan Van Kan G, Rolland Y, Houles M, GilletteGuyonnet S, Soto M, Vellas B. The assessment of frailty in older adults. Clin Geriatr Med. 2010;26(2):275-86.

33. Rogers RG, Boardman JD, Pendergast PM, Lawrence EM. Drinking problems and mortality risk in the United States. Drug Alcohol Depend. 2015;151:38-46. 